\title{
USING PLÉIADES DATA TO UNDERSTAND AND MONITOR A DYNAMIC SOCIO-ECOLOGICAL SYSTEM: CHINA'S POYANG LAKE
}

\author{
Claire Huber ${ }^{1}$, Fengshan $\mathrm{Li}^{2}$, Xijun Lai ${ }^{3}$, Sadri Haouet ${ }^{1}$, Arnaud Durand ${ }^{1}$, Suzanne Butler ${ }^{1}$, James Burnham ${ }^{2-4}$, \\ Claire Tinel ${ }^{5}$, Liu Yizhen ${ }^{6}$, Haiming Qin ${ }^{7}$, Hervé Yésou ${ }^{1}$ \\ 1 : SERTIT- Un. of Strasbourg, Pole d'Innovation, Illkirch, France ; claire.huber@sertit.u-strasbg.fr \\ 2 : International Crane Foundation, E11376 Shady Lane Rd, Baraboo, Wisconsin USA \\ 3 : Nanjing Institute of Geography and Limnology, Chinese Academy of Sciences, Nanjing, PR China \\ 4 : Department of Forest and Wildlife Ecology, University of Wisconsin-Madison, USA \\ 5 : CNES, Analysis and Image Products, Toulouse, France \\ 6 : College of Life Science and Food Engineering, Nanchang University, PR China \\ 7 : Center for Watershed Ecology, Institute of Life Science, Nanchang University, PR China
}

\begin{abstract}
Résumé : Le lac Poyang, première réserve d'eau douce de Chine, est un lac de moussons présentant de fortes variations de surfaces en eau entre la saison sèche, novembre-mars, et la saison humide juin-septembre. Les surfaces en eau passent ainsi de plus de $3000 \mathrm{~km}^{2}$ en été, à moins de $1000 \mathrm{~km}^{2}$ en hiver, cela correspondant à une variation inter annuelle de la hauteur de l'eau de 8 à 12 mètres. En saison sèche, la dépression du Poyang comprend une cuvette centrale en eau de taille réduite, et des lacs déconnectés entourés de vastes zones enherbé es plus ou moins hautes. Lorsque le niveau d'eau augmente, la grande dépression centrale se remplit, puis au fur et à mesure du remplissage, comme une marée montante, l'eau arrive au niveau des lacs, les submerge et l'ensemble forme alors une petite mer intérieure d'eau douce. Cette dynamique et cette amplitude de variations ont de nombreuses implications en termes de ressources en eau, de santé publique (bilharziose), mais aussi de richesse de la biodiversité.
\end{abstract}

Le lac Poyang est un des milieuxles plus riches et les plus importants en termes de biodiversité en Asie du Sud Est. II s'agit d'une zone d'hivernage essentielle pour toute l'avifaune de l'Asie et de Sibérie. Plus de trois cents espèces d'oiseaux dépendent de cet habitat unique dont plus d'une douzaine d'espèces considérées en danger. Les plus emblématiques sont les grues de Sibérie et les cigognes blanches orientales dont la quasi -totalité, 98\% de la population mondiale (moins de 3000 individus) viennent hiverner au Poyang. Cette de grande divers ité d'oiseaux d'eau migrateurs est une conséquence directe de l'hydrologie complexe du lac Poyang.

La forte variabilité intra et interannuelle du remplissage du Poyang, est un phénomène difficile à qualifier, c'est pourquoi un suivi temporel à relative haute fréquence est nécessaire. Dans le cadre de la Recette Thématique Utilisateurs Pléiades, des acquisitions sur une base mensuelle ontété programmées au cours de l'année 2013 couvrant la partie la plus riche et sensible de la Reserve Naturelle du lac Poyang (PLNR). L'exploitation des données a porté sur plusieurs axes. Tout d'abord la caractérisation, à une échelle fine, des trajets de l'eau et de la dynamique de remplissage et de vidange des lacs, mettant en évidence un remplis sage plutôt tardif et peu important au regard des observations réalisées les 12 dernières années, et surtout une vidange très précoce (fin juillet, entrainant par exemple la vidange totale du Bang $\mathrm{Hu}$, principal site d'accueil des grues sibériennes). Les travaux ont également portés sur l'autre principale composant du milieu naturel, la végétation et sa dynamique inverse de l'eau. A partir des relevés terrain, le long de quatorze transects, des indices de végétation ont été exploités afin de réaliser la cartographie de la végétation de ce secteur clé du lac Poyang. Les travaux ont également porté surl'impact des activités anthropiques sur le milieu avec deux atteintes fortes, la mise en place de zones de cultures au sein du Parc national, et l'exploitation du lac Poyang comme carriè re de sable se traduisant par un fort retrait des berges et un creusement des lits mineurs. Enfin, l'exploitation des données Pléiades, associées à des données Cosmo-Skymeda a permis de lever la première carte des filets de pêche au sein de la réserve naturelle. De plus, deux triplets stéréo ont été acquis lors de périodes de basses et hautes marées en mars et septembre 2013, permettant la génération de modèles numériques de surfaces très précis et très détaillés.

Les résultats obtenus suite à l'exploitation des images Pléiades, transmis à l'adminis tration en charge de la gestion du Parc et à une ONG, I'International Crane Fondation, montrent l'apport des données Pléiades pour le suivi environnemental et aussi toutl'intérêt de séries tem porelles très haute rés olution pour la connaissance, et par la même, la protection des milieux.

Mots-clés : Pléiades, végétation, filets de pêche, extraction de sable suivi, inondation, Poyang.

\section{Abstract}

Poyang Lake, the largest fresh water reserve in China, is a monsoon lake characterized by large water surface variations between the dry season, November to March, and the wet season, June to September. This extreme variation and its amplitude over time have a number of implications for the system in terms of water resources, public health (bilharzia/ Schistosomiasis), and also in terms of biodiversity. Poyang's dynamic intra- and inter-annual surface variation is difficult to qualify and to understand using established remotely sensed data techniques and methods. The hydrological dynamism on short temporal scales that Poyang exhibits requires relatively high frequency of monitoring to be effective. Within the Pléiades Users Thematic Commissioning phase (RTU) framework, monthly acquisitions were programmed for 2013 covering the most biodiverse and sensitive part of the lake's oldest protected area: Poyang Lake National Nature Reserve (PLNR). These Pléiades data have been used to precisely delineate water ways, document infilling and 
draining patterns, and to map vegetation based on 14 transects. Finally, this work has looked at human activity impacts on the environment such as the documenting of the establishment of arable farming on National Park borders, sand extraction impacts on waterways, and mapping fish traps in the region. Plus, two stereo triplets have been acquired allowing producing very precise and detailed Digital Elevation Model (DEM).

The results obtained using Pléiades imagery have been transferred to PLNR administration and to the International Crane Foundation, demonstrating the benefits that Pléiades data bring to environmental monitoring. Pléiades imagery and time series offer new opportunities to understand dynamic socio-ecological systems and provide managers and conservationists with novel tools for the administration and conservation of ecosystem function.

Keywords: Pléiades, vegetation community, fish traps, sand dredging, submersion, Poyang.

\section{Context}

The provinces along the middle and lower reaches of the Yangtze River, downstream from the Three Gorges Dam, contain a human population of over threehundred million inhabitants, All of these people directly depend on the services that the wetlands within the Yangtze basin provide: regulating services such as flood storage; provisioning services such as fishing, and host a wide range of biodiversity. China's two largest fresh water lakes, Poyang and Dongting Lakes, are located within this region and are very valuable ecosystems, not only in terms of the biodiversity they maintain but because of their utility and impacts (e.g., disease epidemics) to local human communities found within these systems. Because of their utility and value as socio-ecological systems, Poyang and Dongting lakes are the core of the monitored area within the ESA-MOST DRAGON programme since 2000 (Dragon 2014). This monitoring has allowed characterization of hydrology trends on an intra- and inter-annual basis. A key result is the increase of years with unusually low water levels since the mid 2000's, ie near one year every two years. Because of these observations, it is clear that the state of water resource along the middle and lower reaches of the Yangtze watershed is a major concern. Within this context, the aim of the study was to explore Pléiades potential for water bodies recognition and monitoring, as well as land cover mapping with a focus on wetlands vegetation.

\section{Study area: Poyang Lake}

Located in Jiangxi Province, Poyang Lake is the largest freshwater lake in China and constitutes a major hydrological subsystem of the middle Yangtze basin (Fig. 1). It extends in a hollow depression in the North of Jiangxi Province at very low elevation, approximately ten meters above sea level, surrounded on three sides by several mountain chains.

The watershed of Poyang Lake is about $162,000 \mathrm{~km}$ and includes Jiangxi Province's major river systems, Xiushui, Gan, Fuhe, Raohe and Xin rivers, flowing from the South of Jiangxi province to the North into Poyang Lake. Poyang Lake drainage has a single, narrow outlet into the Yangtze River which serves as the northern border of the province (Fig.1). Poyang Lake undergoes significant seasonal water level variations: surface elevation regularly varies between 9 and $18 \mathrm{~m}$ above sea level and its size fluctuates from less than 1,000 $\mathrm{km}$ during the dry winter period, with extreme minimum about $700 \mathrm{~km}^{2}$, to more than $3000 \mathrm{~km}$ during the wet summer season. During a typical hydrological year, the discharge peak of the Jiangxi's rivers occurs between April and June during the monsoonal rainy season, raising the lake's water level. The lake's tributaries discharge decreases from July to September but this usually offset by rising water levels of the Yangtze. As a result, the drainage from Poyang to the Yangtze River reverses and begins moving from the Yangtze River into Poyang Lake about mid-July.

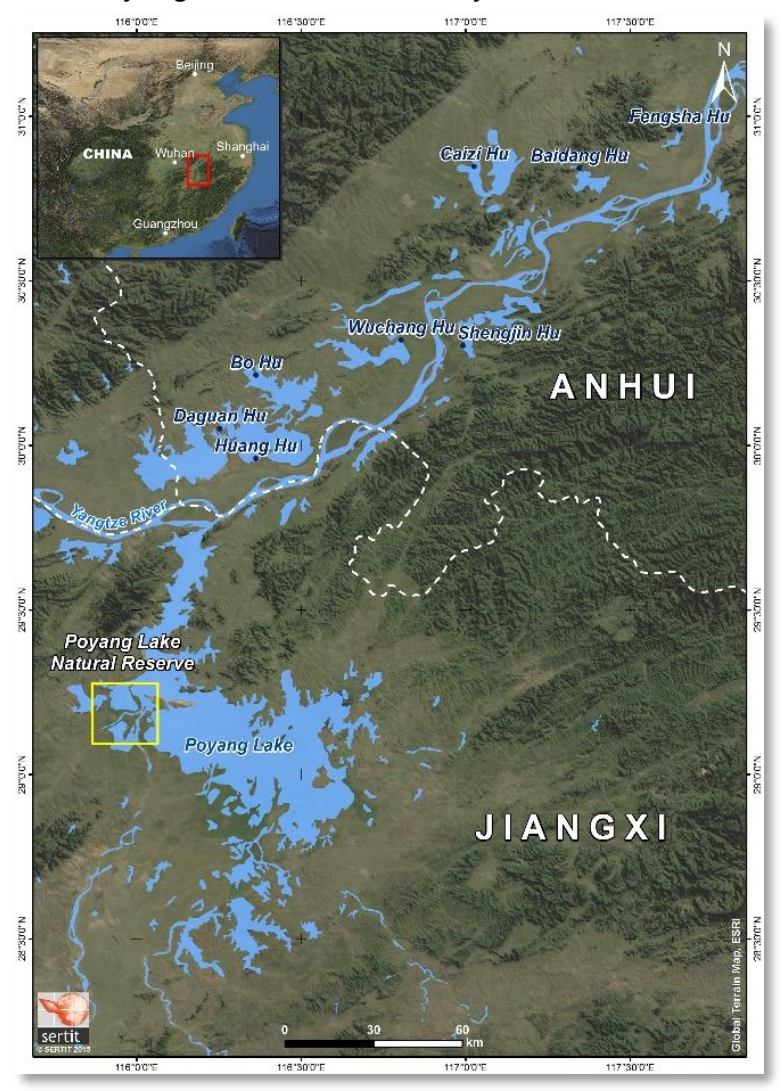

Figure 1 : Location of Poyang Lake within China and Jiangxi Province.

Poyang Lake is of great importance to Jiangxi and other downstream provinces, because it plays an important role in storing floodwaters from multiple tributaries and the Yangtze River, provides water for the many cities and the surrounding rural population, and is an important waterway for river transportation. It is also internationally recognized as key area for biodiversity conservation within Asia, and for some as Poyang Lake represents one of the most important wetlands in the world.

Poyang Lake Nature Reserve (PLNR), with an area of $224 \mathrm{~km}^{2}$, was established in 1983 and promoted as a 
national level reserve in 1988. In 1996, PLNR was labelled as RAMSAR wetland site. This designation recognizes globally important wetland areas typified by a diverse ecosystem and Poyang is an important breeding area for manyfish and shellfish species during the summer flood periods. The lake is also a major wintering area for over 200 species of birds, including twenty threatened or endangered species, such as the Siberian crane and the Oriental white stork.

The area covered by the Pléiades imagerycorresponds to PLNR. This is the oldest, and best studied protected area within this diverse ecosystem. The reserve is made up of several, small lakes that are key wintering areas for cranes including: Bang $\mathrm{Hu}, \mathrm{Da} \mathrm{Hu} \mathrm{Chi}$, Sha $\mathrm{Hu}, \mathrm{Mei} \mathrm{Xi} \mathrm{Hu}$, and Chang $\mathrm{Hu}$ Chi. Regularly these lakes host tens of thousands of tundra swans during the cold period (Fig. 2).

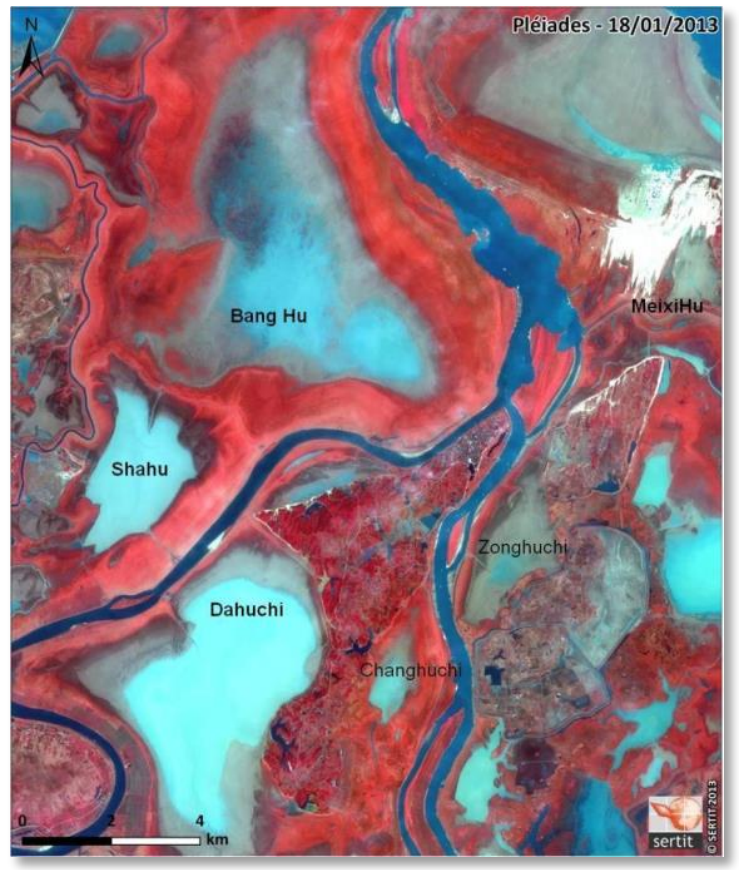

Figure 2: Poyang Lake Natural Reserve as observed by Pléiades on the $18^{\text {th }}$ of January 2013 , low water period.

\section{Exploited satellite and in situ data and data processing}

Over Poyang Lake, a very rich and dense Earth Observation database has been established mostly through the DRAGON projects, but also thanks to bilateral projects with space agencies or data providers such as ASI, JAXA, DLR, DEIMOS or experimental programmes such as Take Five initiative aiming to simulate Sentinel-2 acquisition. This database, covering the years 2000 to 2014 , contains more than 650 medium and high resolution satellite images both optical and SAR (Andréoli et al., 2007; Yésou et al., 2011-2014). Within the thematic comm is sioning phase of Pléiades, 11 Pléiades images $(0.70 \mathrm{~cm}$ resolution in panchromatic mode and 4 spectral bands from blue to Near Infra-Red (NIR), spatial resolution of $2.8 \mathrm{~m}$ ) were acquired over PLNR from January to November 2013 (Table 1).
Importantly, these data nearly cover a complete hydrological year starting in the middle of the dry season (January) and ending at the beginning of the next dry season (November), illustrating low and high level extent of water bodies (Fig.2 and 3).

\begin{tabular}{|l|l|l|l|}
\hline $18-01$ & $12-04$ & $23-07$ & $23-10$ \\
\hline $05-03$ & $22-05$ & $05-08$ & $20-11$ \\
\hline $12-03$ & $18-06$ & $20-09$ & \\
\hline
\end{tabular}

Table 1 : Dates of acquisition of Pléiades data over the PLNR within the Pléiades Users Thematic Commissioning in the year 2013.

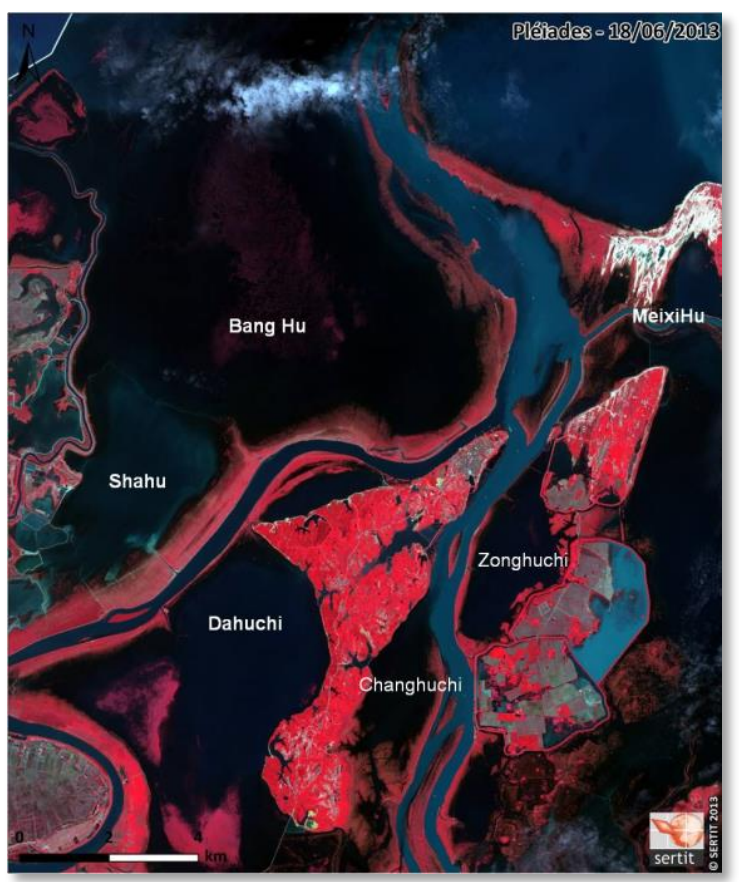

Figure 3 : Poyang Lake Natural Reserve as observed by Pléiades on the $18^{\text {th }}$ of June 2013 ,

high water period, when lakes are connected to one another and neighbouring rivers via surface water.

The power and utility of the imagery database have increased with in situ data. These data include water level surface elevation and discharge coming from gauge stations located within the small Lakes and also along the Yangtze. In 2013 and 2014, an important effort was done to collect information on vegetation within PLNR. Teams from the College of Life Science and Food Engineering of Nanchang University and the International Crane Foundation (ICF), supported by PLNR staff, conducted two major field campaigns on the 20-21 of November 2013, the day of a Pléiades acquisition, as well as on the $10^{\text {th }}$ of April 2014 at the end of the dry season. The number of samples taken along each transect varies from 5 to 10 . For each sample, four sub samples have inventoried dominant plant groups, vegetation height, ground coverage and are accompanied with four photos taken in each of the cardinal directions and looking down from above at from the sample point. This vegetation' dataset has been 
converted into a GIS format in order to be manipulated and exploited for classification purposes.

Pléiades images have been first converted into TOA radiance and then a pseudo atmospheric correction has been applied based on dark object subtraction approach (Chavez, 1988). Data have been then orthorectified and the multispectral and panchromatic channels have been merged.

Water surface extractions have been done based on NIR channel's thresholding approaches followed by on screen correction. A series of tests of classification kernels, based on OTB, distributed as an open source library of image processing algorithms (Christophe et al., 2011; Michel, 2013; Michel et al., 2009), have been performed. Results obtained over the set of images representing various hydrological conditions show that the Support Vector Machine (SVM) based approaches are the best adapted more in regards to image complexity, particularly at the transitional zone between water and wet soil. Furthermore, contrary to what is suggested in the literature, the core "Radial Basis Function" (RBF) is less efficient than the linear kernel core.

The vegetation classification has been done over the multispectral data based on field information derived from the 14 transects. This classification is primarily driven by parameters related to the dominant groups of plants that have been documented. The analysis of spectral signatures over the time series, have leaded to select the three images acquired in March, September and November, as these times represented keys states of life cycle of the plants' groups. Then SVM classification has been carried out based on Vegetation and Brightness indices (NDVI and IB), varying the number of classes and of training areas. Classical post classification processes, opening and closing, has finally been applied. The Final classification consists of 16 classes with 9 extracted vegetation types.

\section{Hydrological analysis based on Pléiades time series}

Water surface monitoring has been ongoing at Poyang Lake for more than 14 years. This analys is of the water surface variation is based on Middle and High resolution data (Yesou et al., 2011; Huber et al., 2013).

Thanks to Pléiades acquisitions ithas been possible to carry out monitoring at a much finer scale: $0.70 \mathrm{~m}$ rather than $30 \mathrm{~m}$, highlighting the hydrological behaviour of the small, biodiverse lakes of PLNR (Fig. 4). The analys is of the HR time series has allowed fine scale monitoring of the small lakes during the hydrological year; from the infilling up to the merging with surrounding water bodies as well as when they have separated again at the draw down time. In 2013, during the end of the water expansion phase, appears to be relatively early, as observed at the end of June. The image acquired at the end of July presents a lower extent of water surface indicating a beginning of draw off of the water. In a more typical year, this shift from increasing to decreasing phase of water bodies usually happens in the fall (mid September to mid October).
This early draw-down is confirmed at the broader lakescale through imagery from Landsat $8, \mathrm{HJ} 1 \mathrm{~A}$ and CSK data analysis (Huber et al., 2014). This broader, ecosystem-level analysis additionally indicates that 2013 can be characterized as drier than normal but with a beginning of the flood period that matches typical starts to the high water season (Huber et al., 2014).

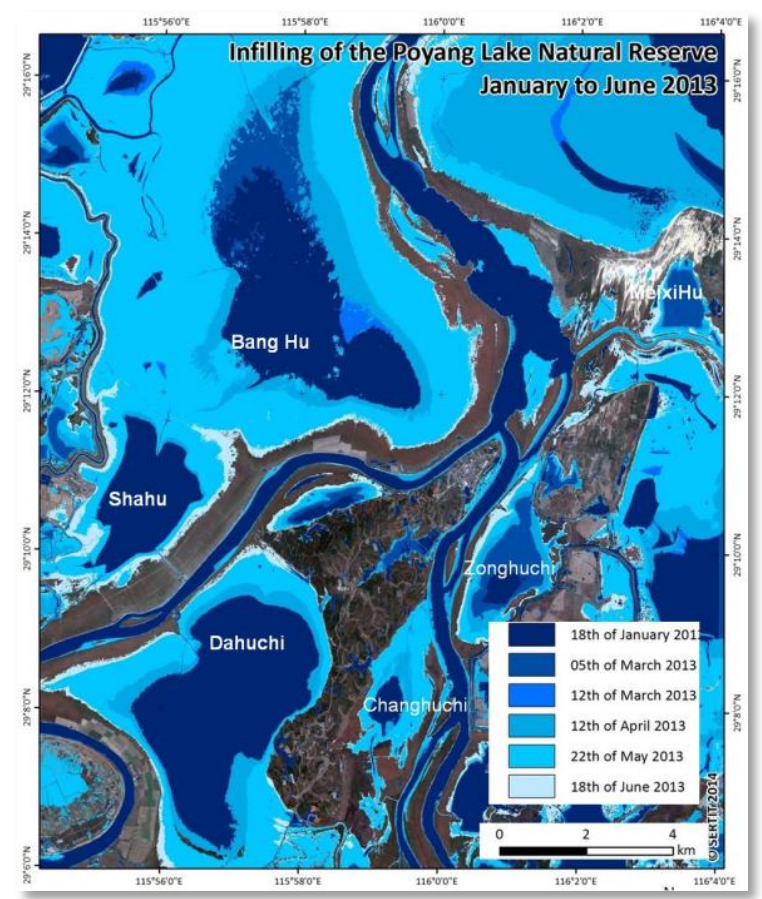

Figure 4: Monitoring lakes water surfaces based on Pléiades time series, covering the infilling period.

From the water extent analysis, it has been possible to generate a time of submersion map (Fig. 5). This map presents perennial water bodies and surfaces under water with a preliminary estimation of flood duration.

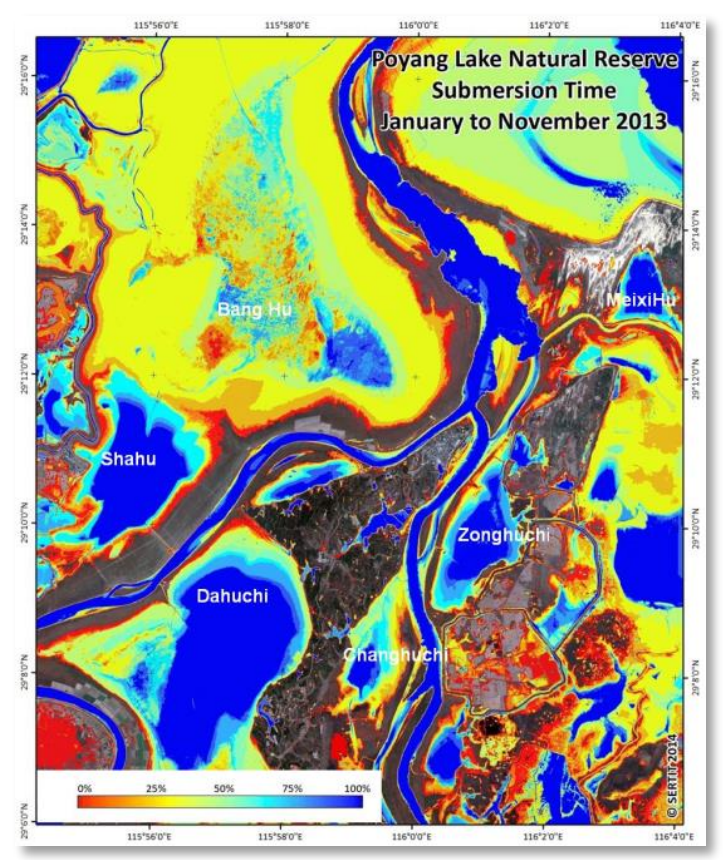

Figure 5: Time of submersion map derived from the Pléiades time series. 
One major highlight corresponds to the large variation of the time of submersion of the lakes within PLNR. There are two opposite examples of this: the relatively stable case of $\mathrm{Sha} \mathrm{Hu}$ representing small variation in size before merging with water coming from Bang $\mathrm{Hu}$.

- The opposite case is illustrated by Bang $\mathrm{Hu}$, which went from flooded during the rainy season to near totally dry only a few months later.

The differences between these two lakes are driven both by topographic configuration, some lakes are fully closed, and the influence of sluice gates which can be opened or closed at various times throughout the dry season depending on the lake. This type of time of submersion map is a powerful representation of complicated hydrologythat is useful for effectiveness of wetland management, as well as education and communications purposes.

\section{Land cover analysis based on Pléiades time series}

As already indicated, based on derived indices from 3 Pléiades XS images and a field survey, a land cover classification focused on natural vegetation has been developed (Fig. 6).

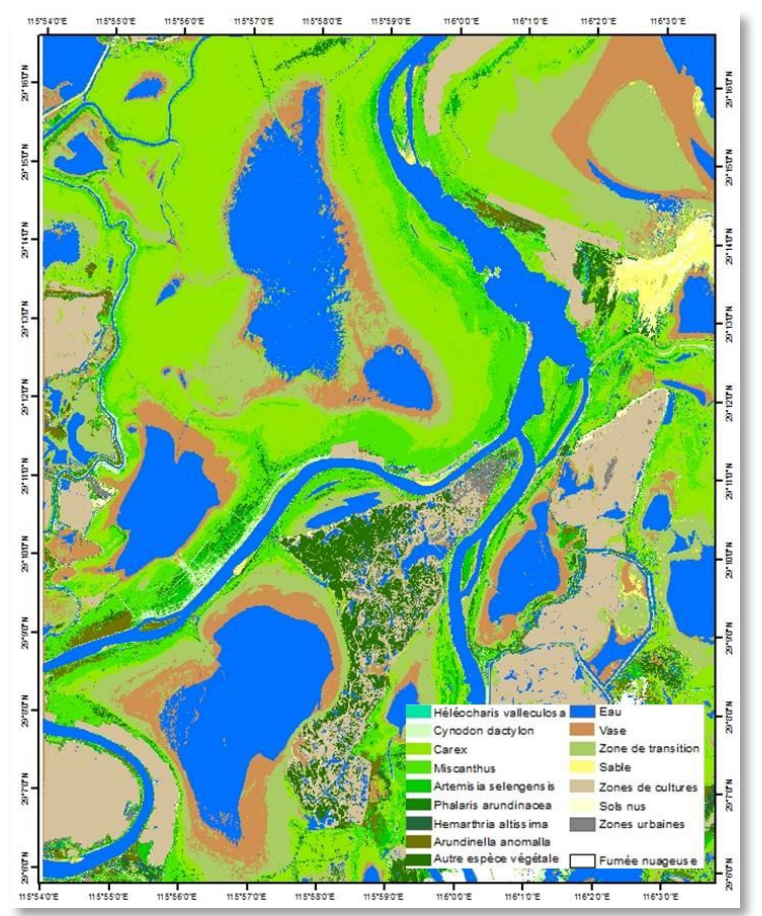

Figure 6 : Land cover classification derived from diachronic Pléiades data.

Within PLNR, a major element is water, covering on average about $25 \%$ of the area, large expanses of carex (a cool season sedge) cover a similar amount of surface as the other dominant landcover. Miscanthus (a warm season grass) with almost $10 \%$ and Artemisia, with less than $3 \%$ of the non-water area are the second and third most dominant groups of vegetation, respectively.

\section{Recognition of human impacts on the Poyang Lake ecosystem}

The lakes along the middle and lower reaches of the Yangtze River have a dynamic and cyclic water cycle thanks to monsoonal precipitation events and are a unique collection of ecosystems with very high amounts of biodiversity. As already mentioned, Poyang Lake is a major wintering area within Asia, with more than 300 birds species, 12 of which are threatened or endangered, depending on the wetland and upland habitats across the lake. In addition to the ability to monitor water surfaces across such a sensitive and dynamic ecosystem, HR Earth Observation imagery is useful for the characterisation of anthropogenic activities, e.g., sand dredging and fishing activities within the system in order to identify their impact on the lake.

Dredging for sand in the middle and lower Yangtze River has been increasing rapidly since the 1980's to supply material for the construction industry across Central and Southern China. These activities seriously have threatened the safety of the river embankment along the main stream of the Yangtze River and sand mining was banned on the mainstream of the Yangtze River in 2001. Dredging operations quickly moved into Poyang Lake and developed into an industry involving hundreds of large vessels. Water quality assessment and monitoring has been carried out based on medium resolution satellite imagery (de Leeuw et al., 2010; Feng et al., 2012).

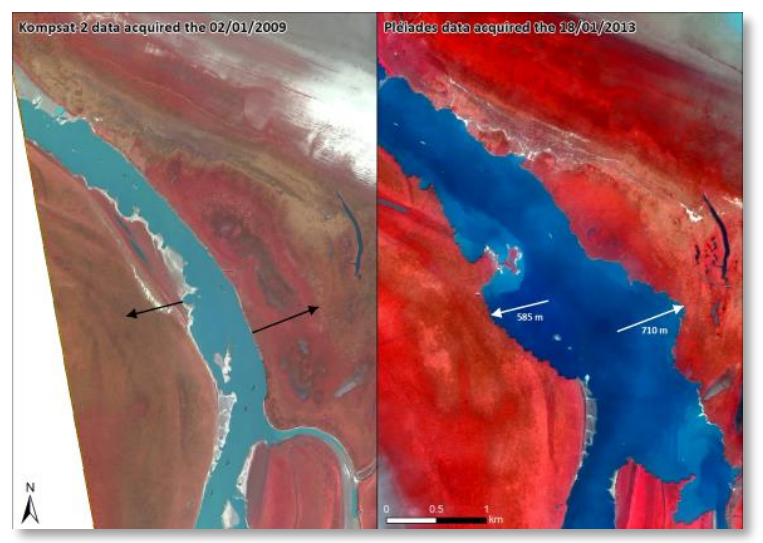

Figure 7 : Comparis on of Gan river banks on the Bang Hu borders based on Kompsat-2 and Pléiades imagery acquired respectively on 02-01-2009 and 18-01-2013.

The comparison of diachronic VHR imagery, such as a Kompsat-2 and Pléiades, acquired respectively in January 2009 and 2013, allows for characterizing the dredging impacts in terms of expansion of channels and disappearance of sandbars within PLNR and on its surrounding areas. Channels and sand banks initially have smooth, linear edges, but now appear irregular and even nibbled (Fig. 7, 8). Thanks to the HR imagery, it is possible to measure precisely the retreat of the channel's banks. For example in the vicinity of the PLNR, along the eastern limit of the Bang $\mathrm{Hu}$, this retreat is more than $500 \mathrm{~m}$ on each side of the main channel of the river. This loss leads to a significant widening of the Gan River which triples its width at this point during low water level in only four years (Fig. 7). 
An indirect impact from sand dredging activities is the expansion of fishing activities utilizing fish traps. Removing sand banks opens some areas of lower water depth, and also dredging activities give an access to areas that were previously unsuitable for this activity during the low-water period. Pléiades merged MS-Pan imagery, with a resolution of $70 \mathrm{~cm}$, was exploited in order to map fish traps. A total of 473 fish traps, ranging in size from $25 \mathrm{~m}$ to $95 \mathrm{~m}$, with a combined length of 107 $\mathrm{km}$ have been identified this way around the sandy islands in the north western portion of Poyang Lake and near the town of Duchang.

The mapped $107 \mathrm{~km}$ of fishing nets are in addition to $500 \mathrm{~km}$ of nets already mapped and located within the main Poyang basin bas ed on ALOS Prism AVNIR data, and $50 \mathrm{~km}$ of nets within Bang Hu derived from a VHR SAR Cosmo Skymed image (Huber et al., 2013). All total, there are at least $667 \mathrm{~km}$ of combined length of fish traps that have been identified within the Poyang Lake system. These activities have been brought to the attention of people in charge of biodiversity analys is and maintenance within PLNR. This knowledge is useful to assess the spatial relationship between fauna, e.g., highly endangered cranes and Yangtze Finless Porpoises, and fish traps. First results from Bang $\mathrm{Hu}$ indicate that areas of crane use are free of nets (Huber et al., 2013).

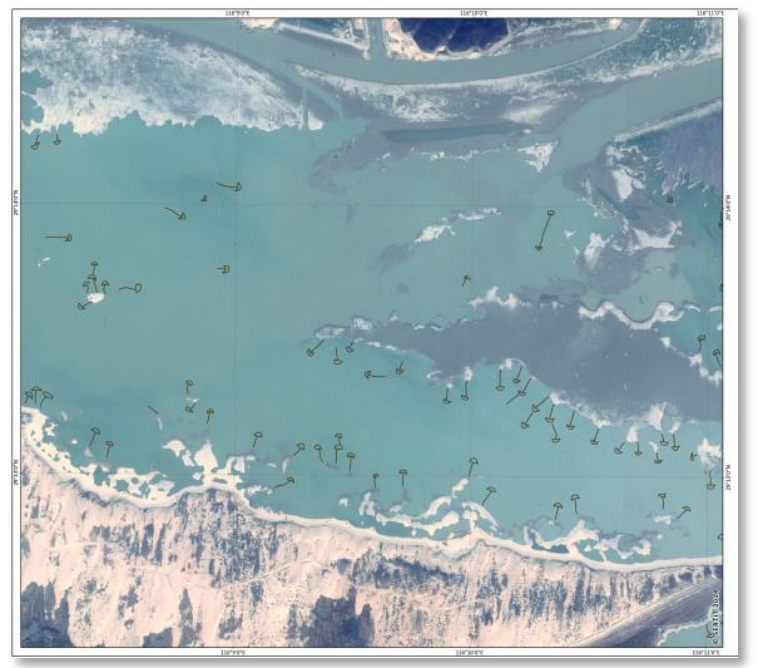

Figure 8 : Fish traps mapping based on Pléiades imagery.

The Pléiades time series revealed other potential damages to the natural environment during the year 2013. For example, these data allowed for the mapping of the conversion of dozens of acres of seasonal grasslands into agriculture production areas near the boundary of PLNR.

\section{Conclusion}

The Poyang Lake case study is the first example of using monthly Pléiades time series within a socioecological ecosystem. Even if it can be delicate to generalize results obtained over a specific area for a wider exploitation of this VHR data, few points have to be be highlighted. This Poyang lake study serves as an important example of how medium and high resolution satellite imagery time series can be exploited for environmental monitoring.

Thanks to the very high resolution, $70 \mathrm{~cm}$, precise characterization of the water ways and the filling and draining dynamics of the sub lakes have been done. This analysis highlights the relatively late and low lake filling, and in particular the very early start of draining at the end July, leading to the complete drying of Bang $\mathrm{Hu}$, one of the principal wintering sites for Siberian Cranes. The work has also mapped the other principal component of the area, its vegetation. Thanks to a rich collection of field data, Pléiades XS vegetation indices have been used to map the vegetation groups within this key sector of Poyang Lake. Finally, this work has looked at human activity impacts on the area's environment with the establishment of arable farming within the National Park and the use of Poyang Lake for sand extraction, which has led to a significant retreat of channel banks and a deepening of stream beds. In addition, the exploitation of the Pléiades, in conjunction with CSK data lead to the generation of the first fish trap maps over PLNR. This represents the first complete high-resolution map of the fish nets over the entire Poyang depression which can be exploited to understand the spatial relationships between porpoises or cranes locations and fishing nets.

The results obtained using Pléiades imagery, transferred to the Park administration and to an NGO, the International Crane Foundation, demonstrate the benefits Pléiades data bring to environmental monitoring. In addition to the very high resolution of Pléiades, the ability to have data over multiple time points is important for the understanding of this dynamic ecosystem and greatly contributes towards helping protect the environment.

\section{Acknowledgements}

The Pléiades (@ CNES (2013), distribution Airbus DS / Spot Image) images have been acquired within the Pléiades Users Thematic Commissioning phase and processed with the support the TOSCA SWOT programme. Authors would like to thanks the CNES ORFEO group, more particularly Claire Tinel and Delphine Fontannaz for their strong, continuous and very efficient support for accessing the data. The Kompsat-2 data was provided within a cooperative framework between CNES and KARI. The authors thank the two anonymous reviewers for their comments which lead to an improvement of the text comprehension.

\section{References}

Andreoli R., Yesou H., Li J., Desnos Y-L., Shifeng H., De Fraipont P., 2007. Poyang Hu (Jiangxi Province, P.R. of China) Area Variations between January 2004 and June 2006 Using ENVISAT Low and Medium Resolution Time Series, Geographic Information Sciences, 13 (1).

Barzen J., Engels M., Burnham J., Harris J., Wu G., 2009: Potential impacts of a water control structure on the abundance and distribution of wintering waterbirds at Poyang Lake. International Crane Foundation. 
Chavez P.S., 1988: An improved dark Object substraction technique for atmospheric scaterring correction of multispectral data. Rem.Sens. Env. Vol (24): 459-479.

Christophe, E., Michel, J., Inglada, J., 2011. Remote sensing processing : From multicore to gpu. Selected Topics in Applied Earth Observations and Remote Sensing, IEEE Journal of 4 (3): 64-652.

Dragon 2014: https://dragon3.esa.int/web/dragon3/home

Feng L., Hu C, Chen X., Tian T., Chen L., 2012: Human induced turbidity changes in Poyang Lake between 2000 and 2010: Observations from MODIS. JGR, 117

Harris J., Hao Z., 2010: An Ecosystem Approach to Resolving Conflicts Among Ecological and Economic Priorities for Poyang Lake Wetlands, Wetlands International ; IUCN, Poyang lake report.

Huber Cl, Huang Sh, Lai X, Chen X., Studer M DailletRochette S., Yésou H., 2014. Yangtze River's connecting lakes hydrological conditions analysis exploiting 14 years of Dragon time series and field measurements. Proceedings Mid Term Results DRAGON3, Chengdu, Sichuan Province, PR China. ESA SP 742.

Huber Cl, Li J, Daillet-Rochette S., Chen X, Lai X., Cretaux JF, Zhang W., Uribe C., Studer M. , Huang Sh, Averty S., Burnham J., Yésou H., 2013: Twelve year of water resource monitoring over the Yangtze middle reaches exploiting DRAGON time series and field measurements. Proceedings Final Results DRAGON2, Beijing, PR China. ESA SP 704.

Leeuw de J., Shankman D., Wu G., Boer de F., Burnham J., He Q., Yésou H., Xiao J., 2010: Strategic assessment of the magnitude and impacts of sand mining in Poyang Lake, China, Regional Environmental Change, June 2010, 40 (2), pp 95102

Michel J, 2013: Machine learning for remote sensing: ORFEO Toolbox meets OPenCV. FOSS4G, Nottingham.

Michel J., Feuvrier T., Inglada J., 2009: Reference Algorithm Implementations in OTB: Textbook Cases. In: IGARSS (4), Cape Town, Southern Africa.

Shankman D., Keim BD, Nakayama T., Li R. Wu D., Remington WC, 2012: Hydroclimate Analys is of Severe Floods in China's Poyang Lake Region, Earth Interactions, 16, 14: 2-16

Yanyan Dong, 2012: Contingent valuation of Yangzte Fonless porpoises in Poyang Lake, $232 \mathrm{p}$

Yésou H., Huang S., Studer M., Lai X, Chen X., Daillet $S ., 2011$ : Nine years of water resources monitoring over the middle reaches of the Yangtze River, with ENVISAT, MODIS, Beijing-1 time series, Altimetric data and field measurements. Lakes \& Reservoirs: Research \& Management, Special Issue: WLC Special Issue, Vol. (16), Issue 3: 231-247.

Yésou H., Huber C., Huang S., Studer M., Lai X, Chen X., Daillet S., 2014: Water resource monitoring based on EO data: Gained experience after 10 years of DRAGON programme over the Yangtze middle reaches. From ERS1 to Sentinel 1, and from MERIS to HJ1 and Pléiades. Proceedings Mid Term Results DRAGON3, Chengdu, Sichuan Province, PR China, ESA SP 742.
Zhang Y., Huber Cl., Yesou H., Lai X., 2014: Remote sensing monitoring of sand mining induced lake surface change and its impact on low water level in Poyang Lake China. Proceedings Mid Term Results DRAGON3, Chengdu, Sichuan Province, PR China, ESA SP 742. 